\title{
UNIVERSITYOF
}

FORWARD

THINKING

WESTMINSTER用

WestminsterResearch

http://www.westminster.ac.uk/westminsterresearch

\section{Personality biases in different types of 'internet samples' can influence research outcomes \\ Buchanan, T.}

NOTICE: this is the authors' version of a work that was accepted for publication in Computers in Human Behavior. Changes resulting from the publishing process, such as peer review, editing, corrections, structural formatting, and other quality control mechanisms may not be reflected in this document. Changes may have been made to this work since it was submitted for publication. A definitive version was subsequently published in Computers in Human Behavior.

The final definitive version in Computers in Human Behavior is available online.

(C) 2018. This manuscript version is made available under the CC-BY-NC-ND 4.0 license http://creativecommons.org/licenses/by-nc-nd/4.0/

The WestminsterResearch online digital archive at the University of Westminster aims to make the research output of the University available to a wider audience. Copyright and Moral Rights remain with the authors and/or copyright owners.

Whilst further distribution of specific materials from within this archive is forbidden, you may freely distribute the URL of WestminsterResearch: ((http://westminsterresearch.wmin.ac.uk/).

In case of abuse or copyright appearing without permission e-mail repository@westminster.ac.uk 
Running head: PERSONALITY BIASES

\author{
Personality biases in different types of 'internet samples' can influence research \\ outcomes. \\ Tom Buchanan \\ University of Westminster
}

Author Note

Tom Buchanan, Department of Psychology, University of Westminster, London, United Kingdom.

Correspondence concerning this article should be addressed to Tom Buchanan, Department of Psychology, University of Westminster, 115 New Cavendish Street, London, United Kingdom, W1W 6UW. Tel. +44 (0)20 3506 9032. E-mail t.buchanan@westminster.ac.uk 


\begin{abstract}
There are different ways of recruiting participants for internet-mediated research. Small differences in personality have previously been documented between participants recruited in different ways. Three online studies investigated whether such personality biases could affect research outcomes. In Study 1, volunteers completing an online personality test scored higher on Openness to Experience than students participating as a course requirement. Study 2 demonstrated that Openness to Experience was associated with political voting preference (Republican v. Democrat). Study 3 found that volunteers scored higher on Openness to Experience than members of a paid research panel. Among volunteers, but not paid panellists, Openness to Experience was associated with voting preference. It is concluded that where research outcomes may be influenced by personality, particularly Openness to Experience, researchers conducting online studies should be aware that biases arising from recruitment techniques could influence findings. Recommendations are made for addressing this issue.
\end{abstract}

\title{
Keywords
}

Internet-mediated research methodology; volunteers; Personality biases; Openness to Experience; Political preference; Participant recruitment

\section{Highlights}

- Volunteers had higher Openness to Experience than a student sample

- Openness to Experience among volunteers is associated with political orientation

- Volunteers had higher Openness to Experience scores than paid participants

- For paid participants Openness was not associated with political orientation

- Personality biases arising from recruitment method could influence research outcomes 


\section{Introduction}

Over the past two decades, internet-mediated research methods such as online surveys have become firmly established in the repertoire of behavioral scientists. Work using the internet and associated technologies for the remote acquisition of data, from or about human participants, is common in many disciplines. For example, Rife, Cate, Kosinski, and Stillwell (2014) contend that internet-mediated studies have become widely accepted within social psychology, and Crone and Williams (2016) note that internet studies are commonplace. There are a variety of ways of sourcing participants for such research. These range from participation requests posted on social media or specialised websites, to commercial research panels and crowdsourced labor marketplaces. Matthijsse, Leeuw, and Hox (2015) argue that most internet-mediated research is based on non-probability panels, comprising selfselected respondents. Given their prevalence, it is important to consider methodological issues that may affect the outcomes of such online studies.

\subsection{Data Quality and Generalizability}

There has always been discussion of issues such as data quality in online data collection. In recent years, the debate has moved on from consideration of the method as a whole, to examination of the data quality characteristics for different sources of data. For example, with the recent popularity of the MTurk online labor marketplace for participant recruitment, there has been a sharp focus on data quality (e.g. Hauser \& Schwarz, 2016; Lowry, D’Arcy, Hammer, \& Moody, 2016; Thomas \& Clifford, 2017) and other characteristics such as the extent to which MTurk studies may be repeatedly sampling from a limited participant pool of 'expert' respondents (Stewart et al., 2015). Similar themes are seen in methodological research on other participant 
sources: for example, Matthijsse et al. (2015) identified a subset of 'professional' respondents who were members of multiple online research panels, but whose presence did not seem to affect data quality.

In addition to data quality, a common theme of discussion has been the extent to which findings obtained with different types of online sample may be generalizable to wider populations. Hays, Liu and Kapteyn (2015) discuss the representativeness of both opt-in (convenience) and probability-based internet respondent panels. They note that samples drawn from convenience panels can be weighted to improve demographic representativeness, but this "does not always yield complete comparability of the outcome measures to a target population" (p. 687), for example in terms of self-reported health status. There is considerable other evidence that selfselected volunteer samples may vary from probability samples in terms of a number of characteristics, and perhaps particularly in terms of their status with respect to the topic of a study (e.g. Khazaal et al., 2014).

\subsection{Psychological Differences Between Volunteers and Other Research}

\section{Participants}

There is evidence going back some time (e.g. Oakes, 1972) that there may be psychological as well as demographic differences between self-selected volunteers and people recruited in other ways. For example, Van Lange, Schippers and Balliet (2011) found that people who volunteered to take part in experiments were more likely to be prosocially-oriented than those who did not. In the context of internetmediated research, this raises the possibility that people recruited in one way (for instance volunteers responding to an advert circulated via social media) may differ psychologically from those recruited through other routes (for instance a paid online research panel). The reason this matters is summed up nicely by Oakes: "For any 
behavioral phenomenon, it may well be that members of another population that one could sample might have certain behavioral characteristics that would preclude the phenomenon being demonstrated with that population." (Oakes, 1972, p. 961). Expressed more crudely: one might find a given effect in one sample, but not another, due to psychological differences between them.

While this notion has been present in the literature for some time (e.g. Buchanan, Johnson \& Goldberg, 2005) it has received little empirical scrutiny. One exception is work by Rife et al. (2014) who compared personality data for volunteers recruited through Facebook and through a stand-alone data acquisition website. While both were volunteer samples, they were different types of volunteer. The Facebook participants actually paid a fee to take part, which is very unusual. There were personality differences, of which the largest was in Openness to Experience (higher in the Facebook group). However, effect sizes were small, leading Rife et al. to argue that these differences arising from recruitment method were not likely to affect research outcomes. Rife et al. also compared Facebook participants with an undergraduate sample, drawn from a University participant pool. Again, there were personality differences, of which the largest was in Openness to Experience (again higher in the Facebook group). The personality trait of Openness to Experience broadly reflects an interest in culture, arts and educational experiences; imagination and creativity; and progressive rather than conventional outlooks. It is known to be associated with a range of behavioral phenomena (e.g. Buchanan, Johnson \& Goldberg, 2005; Costa \& McCrae, 1992).

Rife et al. argued that the differences they found were too small to have a realistic prospect of influencing research outcomes, and that this supported the view 
that Facebook was a viable medium for participant recruitment and testing. However, there is scope for bigger differences to exist between volunteers of the type they tested, and other participant types (such as financially-motivated research panel members). There were also minor differences between their recruitment routes in terms of the materials used that could conceivably have attenuated the effect sizes for the differences they did report. Finally, the fact that an effect is small, does not always mean it has no practical significance. For example, even a small difference in the efficacy of two drugs could lead to differences in the number of lives saved depending on which is prescribed. Therefore, there is still a question here worthy of examination.

\subsection{Aims, Research Questions and Hypothesis}

There are different ways of recruiting samples for research projects executed via the internet. It is possible that different types of sample will have different personality characteristics (for example, volunteers may be more Open to Experience than people recruited in other ways). Evidence to date suggests that if differences exist, they may be too small to be practically important. The overall aims of this project were to establish (1) whether there are personality differences between different types of internet sample, and (2) if there are, are they likely to affect research outcomes?

These research questions were addressed with a series of three studies. Study 1 was intended to test for the existence of personality differences between samples recruited in different ways. Study 2 was designed to establish that a phenomenon of interest to researchers was influenced by the personality variable(s) in question. Study 3 tested whether recruiting participants in different ways could actually make a difference to research findings. For Study 1, it was specifically hypothesised that 
volunteers recruited via the internet would have higher Openness to Experience scores than members of a traditional undergraduate research panel.

\section{Study 1}

Study 1 used a quasi-experimental design to compare the personality profiles of participants recruited either through a personality testing website, or a University research participation scheme. Ethical approval for the study came from the host University’s Psychology Research Ethics Committee.

\subsection{Method}

2.1.1. Materials. In both conditions, data was collected using an online 41item personality questionnaire (Buchanan, Johnson \& Goldberg, 2005) derived from the International Personality Item Pool (IPIP; Goldberg, 1999). The measure provides indices of Extraversion, Neuroticism, Openness to Experience, Agreeableness and Conscientiousness that correlate well with the domains of Costa and McCrae's (1992) Five Factor Model, and has been validated for use on the internet (Buchanan et al, 2005). Participants are asked to rate the accuracy of statements about their typical behaviour on a 5-point scale ranging from 1 "very inaccurate" to 5 "very accurate".

2.1.2. Procedure. In Condition 1 (henceforth, 'the website condition"), participants were recruited using an established personality testing website, www.personalitytest.org.uk. This has existed for a number of years, and attracted over a thousand users per week at the time the study was conducted. No attempt is made to recruit respondents or otherwise attract them to the site - they are referred by other sites or find it through search engines. Many complete the test as part of some class, being asked to do so by their teacher or professor. In Condition 2 (henceforth, 'the course requirement condition'), participants were recruited through the host Psychology department's research participation scheme and referred to the personality 
testing site described below. Students in their first year of study complete a number of hours of research participation in return for course credit.

The conditions differed only in the source of the participants: the experience and materials for participants in both conditions were the same. Participants first saw information about the study. On indicating consent, they moved to a second page with brief instructions and the questionnaire. Radio button response formats on a 5-point scale ('Very Inaccurate - Very Accurate') were used for the personality items, while all the others used drop-down menus. Demographic items comprised age group (in 5year increments); current location (a comprehensive list of nations); gender; highest level of education; main occupational status. Following this, participants were asked how they came to be taking the test (e.g. as part of a class). Finally, participants were asked whether their data could be used in analyses (they were instructed to answer 'no' if they had not answered the questions seriously, or did not give consent). After doing this, those who had completed all the personality items then saw a debriefing page thanking them for their participation, and providing their scores on each of the scales (those who had not were sent back to complete the missing items). In addition, they were given information to help interpret the scores, including a brief description of the meaning of each of the scales, and normative information about their scores relative (top third, middle, bottom third) to others who had completed the inventory to date. Links were provided to contact the researcher, and to information about personality research elsewhere on the internet.

The target sample size was determined based on Ferguson's (2009) 'minimum practical effect size' - i.e. sufficiently large to detect effects that will have real-world importance, as opposed to just statistical significance. These effect sizes are operationalised as equivalent to a Cohen's $d$ of .41. Power analyses indicated that a 
sample size of 300 , with 150 in each condition, would have over $90 \%$ power to detect such an effect. In actuality, recruitment for the course requirement condition ceased before this target was reached. This was because the host University closed the participation scheme through which participants were recruited during a curriculum redesign. No analyses were performed prior to recruitment being terminated.

2.1.3. Data screening and processing. In the website condition, participants were drawn from the general body of people accessing the personality testing website $(19,408$ data submissions). A number of checks were performed to assure data quality. First, any that did not indicate their data could be used were deleted, leaving 13742 records. Data were then screened for multiple submissions, where respondents accidentally or deliberately submit their responses more than once. To guard against this, an ID code is randomly assigned each time the site is accessed. Using the SPSS 23 'Identify Duplicate Cases' procedure, 1439 cases were identified as duplicating another record in the file in terms of the randomly assigned ID code. These were deleted, leaving 12303 cases with unique ID codes. Then, anyone reporting their age group as below 16 years (359 cases) or who did not give their age (11 cases) was removed due to concerns about their capacity to give valid consent. Finally, anyone in the 16-20 group claiming to have completed 'some postgraduate' or greater education (10 cases) was removed due to concerns about mischievous or careless responding. Following these checks, 11923 individuals remained in the dataset collected from the website. Subsets of these 11923 who met the inclusion criteria for the analyses that follow are described in Table 1.

Of 101 individuals who participated in the course requirement condition, two did not indicate they gave consent for their data to be used, and seven cases were found where data submissions were duplicates of other entries in the datafile (e.g. 
where a respondent had accidentally or deliberately submitted data twice). These nine cases were removed, leaving 92.

Two analyses were performed using different sets of participants. For the primary analysis (Analysis 1), a subsample was created by selecting those respondents who were (a) students, (b) located in the UK, and (c) not completing the test as part of some class requirement. This resulted in a 'website condition sample' of 234 individuals who matched those in the course requirement condition in terms of student status and nation, but differed in their motivation to complete the test (course requirement vs. true volunteers).

2.1.4. Participants. Demographics for those Study 1 participants meeting the inclusion criteria for the analyses are shown in Table 1. The data suggest that for Analysis 1, the sample of 326 participants is comprised of UK-based students, mainly younger than 20 years in age, and predominantly female. For Analysis 2, the sample of 6693 participants still comprises around half students, this time all based in the USA. It includes more older people, with higher education levels, and more people in employment. The sample is again predominantly female.

\subsection{Results}

2.2.1 Analysis 1. Personality scores for Study 1 participants are shown in Table 2 (left hand side). Independent samples $t$-tests (Table 3 ) indicated that there were statistical differences between the website volunteer condition and the course requirement condition only in terms of Openness to Experience, with the volunteers being more Open to Experience than those recruited through the participant pool. However, Levene's test for equality of variances also indicated heterogeneity of variance between conditions for Extraversion, Agreeableness and Neuroticism. Volunteer respondents were more variable in these characteristics. One reason for this 
could be increased variability in the website condition with respect to other demographic variables that influence personality. Indeed, $\chi^{2}$ tests indicated that age group $\left(\chi^{2}(7, N=326)=19.36, p<.005\right)$ and $\operatorname{sex}\left(\chi^{2}(1, N=321)=13.17, p<.0005\right)$ were not evenly distributed across conditions. The main analysis was therefore repeated using ANCOVAs examining the effect of Condition and Sex on each personality variable, with age group as a covariate. When these variables were controlled for, there were no differences between conditions in terms of personality scores. In particular, there was no statistically significant difference between volunteers and participant pool members on Openness to Experience $\left(F_{(1,316)}=.1 .66, p\right.$ $=.20)$.

At first glance, the implication of this analysis would be that the two samples do differ in personality (Openness to Experience). However, further analyses showed this is a function of known demographic influences on personality, which can be controlled for. One issue with this interpretation is that samples tested via the internet are often very much larger than the groups compared here. There may still be meaningful differences between recruitment methods that would manifest with larger samples. Given that a large amount of data was collected but not used in Analysis 1, there was scope for additional exploratory analyses to be carried out.

2.2.2. Analysis 2. This exploratory analysis drew on the larger dataset $(N=11,923)$, of which the Analysis 1 website condition sample was a subset. To control for any between-nation differences in personality, analysis was restricted to those 6693 individuals who gave their location as the US. Thus, none of the participants (all from the UK) in Analysis 1 were also included in Analysis 2. Personality scale scores for these participants are shown in Table 2 (right hand side). Those individuals who reported doing the test as part of a class requirement 
(analogous to the course requirement condition in Analysis 1) were compared to those who reported coming to it in some other way, using two-way ANCOVAs, with routeto-participation and sex as independent variables and age group as a covariate. As there was missing data on sex for 140 respondents, the group sizes were 4099 (class requirement) and 2454 (non-required) respectively.

The results of the route-to-participation main effect in these ANCOVAs are summarised in Table 4 (Table 5 includes full information on all five ANCOVAs including the covariates). With this larger sample, there are statistically significant differences between self-reported routes to participation on all personality variables. People seeking out the personality website and participating of their own volition were less Extraverted, Agreeable and Conscientious, but had higher Neuroticism and Openness to Experience, than those participating as part of class requirement.

Given the large sample size, examination of effect sizes is more instructive than statistical significance. All the effect sizes are in the trivial to low range. The strongest effect, for Openness to Experience at 0.03, does not meet the benchmark for partial eta squared (0.04) proposed by Ferguson (2009) for a 'practically meaningful' effect.

\subsection{Discussion}

Analysis 1 suggested that there was a personality difference between volunteers accessing a personality testing website and a traditional undergraduate panel, with the volunteers having higher levels of Openness to Experience. However, the difference was small and could be attributed to known demographic variables. A further exploratory analysis, with a larger sample and thus better power, indicated that volunteers differed from respondents completing the test as a class requirement on all five dimensions of personality. However, the effect sizes were very small. Even the 
largest, Openness to Experience, was below the threshold where it might be considered to be a meaningful difference. These results closely parallel those of Rife et al. (2014). Taken together, these findings suggest that personality biases may be detectable, but it is questionable whether they are worth worrying about in practice. To address this question, Studies 2 and 3 were planned to examine whether the differences observed actually could potentially influence research findings.

\section{Study 2}

Study 1 suggested that samples recruited in different ways could differ in personality, notably Openness to Experience. However, the small effect sizes raised the question of whether such biases actually matter. Study 2 set out to explore whether variables such as Openness could affect phenomena of interest to researchers, and whether differences of the magnitude seen could potentially affect research outcomes.

There is considerable evidence that Openness to Experience is associated with political preference, with people scoring lower on Openness being more conservative in their opinions, and people scoring higher being more liberally oriented (e.g. Carney, Jost, Gosling \& Potter, 2008). Indeed, items asking about voting preference have been included in personality inventories as indices of Openness to Experience: the Openness scale used by Buchanan et al. (2005) includes the items "Tend to vote for conservative political candidates" and "Tend to vote for liberal political candidates". Thus, it was hypothesised that Openness to Experience would be positively associated with a tendency towards political liberalism. In a U.S. political context, participants preferring to vote Democrat would be higher on Openness than participants preferring to vote Republican. 
Study 2 thus used a quasi-experimental design to compare the Openness to Experience scores of U.S. based participants, recruited through a personality testing website, who indicated preferences for voting for either Democrat or Republican candidates. Ethical approval for the study came from the host University's Psychology Research Ethics Committee.

\subsection{Method}

3.1.1. Materials and procedure. Data were collected using the same materials and procedure as in Study 1 Condition 1: a Five Factor personality questionnaire hosted on the website www.personalitytest.org.uk. All participants were visitors to that website, with no active attempts being made to recruit respondents. The materials and experience of participants were identical to those in Study 1, save for addition of a new item at the end of the questionnaire asking about voting preference: "This question applies only to people who are entitled to vote in the USA. In general, do you prefer to vote for Democrat or Republican candidates?". Response options were (1) Prefer not to answer; (2) Not applicable - not entitled to vote in USA; (3) Prefer to vote Democrat; (4) Prefer to vote Republican; (5) Prefer to vote neither Democrat nor Republican.

3.1.2. Data screening and processing. Over a period of 9 days, 1862 responses were logged. Any cases where respondents did not indicate their data could be used were deleted, leaving 1299. Twenty-four individuals who reported an age group of below 16 were excluded. The SPSS 23 Identify Duplicate Cases dialogue was used to identify 96 cases duplicating another record in the file in terms of the randomly assigned ID code. These were deleted leaving 1179 cases. To check for mischievous or careless responding, cases in the 16-20 group were checked for any 
claiming to have completed 'some postgraduate' or greater education. None were found.

3.1.3. Participants. Demographics for Study 2 participants are shown in Table 6 (left side). The data suggest that while there was considerable variance among participants, the majority were relatively young female students based in the United States, who were participating as part of some educational activity.

\subsection{Results}

Descriptive statistics for the personality scales are shown in Table 7. Because the Openness to Experience scale included two items explicitly referring to political preference, an abbreviated version of this scale was also computed which omitted these items. It correlated $r=.91(n=1179, p<.0005)$ with the full Openness measure. This abbreviated measure was used in the following analyses. All scales had acceptable reliability, with Cronbach's alphas $>.7$.

The analysis was restricted to those 804 individuals who reported their location as being in the USA. Of the 777 of those who answered the voting question, $129(16.6 \%)$ preferred not to indicate a voting preference; $65(8.4 \%)$ were not eligible to vote, $332(42.7 \%)$ preferred to vote Democrat, $164(21.1 \%)$ preferred to vote Republican, and 87 (11.2\%) did not prefer either. Data was missing for 27 individuals who did not answer the question.

An independent samples $t$-test was used to compare the Openness to Experience scores of Republican and Democrat voters, using the abbreviated (nonpolitical) Openness scale. This indicated that Democrat voters $(N=332, M=19.80$, $S D=4.08)$ were more Open to Experience than Republican voters $(N=164, M=17.81$, $S D=4.19)$. The difference was statistically significant $\left(t_{(494)}=5.08, p<.0005\right)$ with an effect size of Cohen's $d=0.48$. 
In a further exploratory analysis, a logistic regression was performed to examine the effect of (non-political) Openness to Experience, the other personality variables, age group and sex on classification of participants as either Democrat or Republican voters. This is shown in Table 8 . The Cox and Snell $R^{2}$, at .088, indicated that this set of variables accounted for only a small portion of variance. However, Openness, Conscientiousness, sex and age group were all significant predictors of voting preference. The effect of most interest here is that of Openness. The Odds Ratio for Openness of $0.89(p<.0005)$ indicated that for every one-point increase in Openness to Experience, the likelihood of voting Republican decreases by around $11 \%$.

\subsection{Discussion}

Study 2 showed that, consistent with previous research, there is a relationship between Openness to Experience and political preference. US-based participants preferring to vote for Democrat candidates scored higher on Openness than those preferring to vote Republican. The logistic regression analysis showed that the impact of personality on political preference is modest. However, when considering the potential effect of sampling differences on research outcomes, it is pertinent to recall that Study 1 found the mean Openness to Experience scores of participants recruited in different ways differed by up to 2.2 scale points (Table 4 ). With a one-point difference in the shortened Openness scale used here changing political preference by around $11 \%$, this may mean there is a real possibility that research findings could be affected by recruitment method. The acid test of whether the phenomenon described here actually matters in practice, will be to look at whether different patterns of results are observed in different types of 'internet sample'. This was the focus of Study 3.

\section{Study 3}


Study 3 adopted a quasi-experimental design, where participants recruited through a personality testing website (as in Study 1 Condition 1, and Study 2) were compared with paid individuals drawn from a commercial research panel. The goals of the study were (1) to compare Openness to Experience scores of the two samples, hypothesising that the scores of volunteer participants would be higher than those of paid panellists, and (2) to test whether the relationship between personality and voting preference was replicated across these different types of sample. Ethical approval for the study came from the host University's Psychology Research Ethics Committee.

As an aside, the focus of Study 3 is somewhat relevant to current social concerns. In recent years, there have been concerns about the accuracy of political opinion polls. There have been several high-profile instances where electoral results varied from predictions, with one notable example being the 2015 UK General Election. Analyses of that situation have indicated that unrepresentative sampling was an important factor (Sturgis et al, 2017). Many opinion polls are conducted using participants sourced from online panels, and there is evidence that online panels are typically more Democrat-oriented (in the US) than samples that are more representative of the population as whole, such as telephone random digit dialling surveys (Kennedy et al, 2016). Thus, if some types of sample incorporate biases that could affect the outcomes of political research, it may be important to know about that.

\subsection{Method}

4.1.1 Materials. In both conditions, data was collected using the same 41-item personality inventory as in Studies 1 and 2. For this study, it was hosted on the Qualtrics online research platform (participants accessing the www.personalitytest.org.uk site were automatically redirected to the Qualtrics implementation). Qualtrics' proprietary technology prevented multiple data 
submissions. An additional scale was added to the questionnaire: the ten-item Openness to Experience subscale from the Big Five Inventory (BFI; John, Naumann $\&$ Soto, 2008). This was selected for use as the dependent measure in the study, because unlike the Openness scale in the Buchanan et al. (2005) measure, it does not include any items referring to political preferences. It can thus be used in complete, not abbreviated, form for this study. Beyond this, the materials were as described in Study 2.

4.1.2. Procedure. In Condition 1 (henceforth, 'the volunteer condition'), participants were recruited through www.personalitytest.org.uk in the same way as in Study 1 . They included both true volunteers, and those participating as part of an educational program. In Condition 2 (henceforth, 'the paid condition'), participants were supplied by the Qualtrics research company, drawn from a panel of paid survey respondents. The amount paid to each participant is not known, but is likely to be modest. The experience of participants was as described in Study 2, with the exception that the ten extra BFI Openness to Experience questions were included in the personality questionnaire, and age data was collected in exact numbers of years rather than age groups. Study 1 found an effect size of $d=.32$ for the difference in Openness between volunteers and non-volunteers (Table 3). Sample sizes for Study 3 were planned to give over $95 \%$ power to detect such an effect, with a target of at least 255 in each condition.

4.1.3. Data screening and processing. In the volunteer condition, 18,420 data submissions were recorded from individuals accessing the personality testing website. From the 10,643 who gave consent for their data to be used in analyses, 299 individuals reporting their age as below 16 years were removed from the sample due to ethical concerns about consent, as were 172 who did not answer the age question. 
Two individuals giving unrealistically high ages (150 and 269) and 23 who appeared to have given their year of birth rather than age were also removed. This left 10,147 respondents who gave an age that fell within these parameters. Data quality was further assured by examining the datafile for unrealistic combinations of demographic data (e.g. people claiming to be children with doctoral degrees) that might indicate mischievous or careless responding. Anyone under 21 claiming to have a doctoral or professional degree (15), anyone under 19 claiming to have a Masters degree (2), and anyone under 18 claiming to be a college / University graduate (1), was excluded leaving 10,129 in the sample for the volunteer condition.

In the paid condition, 350 responses were recorded from individuals sourced via the Qualtrics panel. Of these, 49 did not give consent for data analysis, and were thus excluded. An age was recorded for 299 individuals (the two who did not respond to this item were also excluded). All reported ages were between 18 and 25. The datafile was again checked for unrealistic combinations of demographic data. One individual aged under 21 claiming to have a doctoral or professional degree was excluded, leaving 298 in the sample for the paid condition.

4.1.4. Participants. Demographics for Study 3 participants are shown in Table 6 (right hand side). As in the previous two studies, the sample was largely US-based, young and well educated, with a majority of participants being female. Typical ages were a little higher than in Studies 1 and 2.

\subsection{Results}

Descriptive statistics for the measured personality variables are shown in Table 7. While all variables are included for the sake of completeness, the analyses that follow use only the BFI Openness scores. 
To test the hypothesis that online volunteers differed from paid panellists in BFI Openness to Experience, a subsample of the volunteer condition demographically similar to the paid condition was selected. The selection criteria were that the participants had been searching for personality tests (i.e. volunteers finding it of their own accord), were located in the US, aged 18-25 years, and were either students or employed (including self-employed). There were 247 such individuals. Given that demographic variables are known to affect personality, and could differ between the samples, the extent to which gender, age and education were related to BFI Openness to Experience was assessed. Men and women did not differ in BFI Openness to Experience $\left(t_{(541)}=1.31, p=.16\right)$, and BFI Openness to Experience did not correlate significantly with either age $(r=.08, N=545, p=.065)$ or education $(r=.006, N=543$, $p=.89$ ). Thus, analysis proceeded with no controls for these demographic variables being implemented. The BFI Openness to Experience scores of online volunteers $(N=245, M=39.28, S D=6.06)$ and paid panellists $(N=298, M=37.21, S D=5.64)$ were statistically significantly different $\left(t_{(541)}=4.12, p<.0005\right.$, Cohen's $\left.d=0.35\right)$.

The principal question addressed by this study was whether samples recruited in different ways might give rise to different research findings. Therefore, the analysis performed in Study 2 - comparison of the Openness to Experience levels of Democrat and Republican voters - was repeated within each condition, to test whether the relationship between political preference and Openness to Experience was the same for paid participants as it was for volunteers. The same selection criteria as described above were retained to make the two conditions as comparable as possible, apart from having been recruited in different ways. Results of this analysis are shown in Table 10. $t$-tests performed within each condition showed that among online volunteers, people preferring to vote Democrat once again had higher Openness to Experience scores. 
However, this phenomenon was not observed among participants recruited through the Qualtrics panel.

\subsection{Discussion}

Participants recruited through a Qualtrics panel, and volunteers accessing a personality testing website of their own volition, did not differ in variables associated with Openness to Experience other than the manner in which they were recruited. However, consistent with expectations, the volunteers were more Open to Experience than individuals who were paid to participate. This indicates that recruitment method is associated with personality differences. With respect to the question of whether this relatively small difference actually matters, the current findings suggest that it can. The phenomenon reported in Study 2 - association of Openness to Experience and voting preference - was found for one group but not the other.

\section{General Discussion}

This series of studies has shown that samples used in internet-mediated research may vary in their personality characteristics according to the means by which they were recruited. The differences are most notable for Openness to Experience. Volunteers participating of their own volition score higher on Openness than either traditional undergraduate samples, or paid research panel members. The effect sizes for these differences are very small. In many research projects they will be unimportant, as argued by Rife et al (2014). However, where this manuscript goes beyond previous research is to provide a demonstration that these differences actually can influence the outcomes of research. In cases where the phenomenon or dependent variable of interest is related to Openness to Experience, there is potential for recruitment method to affect research outcomes. This is demonstrated by the findings of Study 3, where a known psychological effect was detected with one sample but not 
another. Thus, researchers should consider possible biases arising from self-selection when planning and interpreting studies.

The finding that volunteers are higher in Openness to Experience is not at all surprising. Such individuals are by their very nature intellectually curious, and attentive to their inner states. It is thus entirely likely that people seeking out personality tests on the internet—which is how they would have first come into contact with the personality testing website - would tend be higher on Openness. Furthermore, Dollinger and Leong (1992) found that individuals higher on Openness to Experience were more likely to give permission for data about them to be used in research. This is analogous to the volunteer participants in the current study giving consent for their scores to be used in the project.

\subsection{Limitations}

The work reported here has a number of limitations. While the paper refers to 'online volunteers' in fairly broad terms, there are different categories of these. The current project used people who participated as a consequence of looking for an online personality test. There are other 'online volunteers' who are recruited through websites that actively seek to recruit research participants. Would such individuals have similar personality characteristics to the sample used here? Similarly, there are

other types of paid research participant. Would individuals recruited via online labor marketplaces such as MTurk have similar characteristics to the Qualtrics panellists used here?

The measure of political preference used here was crude in relation to the methodology used in real political polling, or research that focuses specifically on political psychology. However, given that Studies 2 and 3 were intended to provide proof of concept, rather than explore political preference in detail, that seems 
relatively unimportant. The key point is that the hypothesised phenomenon was detected, no matter how crude the measure used.

In Study 3, the total number of Republican voters (105) was markedly lower than Democrats (270), for both the volunteers and the paid panellists (Table 10). This is potentially indicative of the very bias documented in this paper; that people lower in Openness (indexed in this instance by political preference) are less likely to be engaged in online research.

\subsection{Recommendations}

Despite the limitations, the work described here does appear to have implications for practice and a number of recommendations can be made. The key point is clearly that researchers should take the source of their participants in to account and consider whether it could affect research findings. Fortunately, there are some fairly clear ways in which this can be done.

Early work on online research methodology (Reips, 2000) suggested that selfselection effects could be detected using the 'multiple site entry' technique, where data supplied by participants from different recruitment websites is compared. This approach may be a viable one in establishing whether a suspected bias has in fact affected research outcomes. Researchers conducting online studies where Openness to Experience may be an important variable should consider using this approach.

Another implication is for replication efforts. Psychologists have recently demonstrated increased attentiveness to the need for research findings to be replicated. Some replication efforts have involved use of internet-mediated research methods. There has been much discussion of the fact that successful replication rates appear to be lower than one would desire. The implications here are twofold: first, it may be that some failures to replicate have been a function of differences between the 
participants in the original and replication studies (cf. Study 3). Second, it may well be that replications should also be conducted using participants from different sources, to increase confidence in the generalizability of findings.

Finally, although the measure of political preference used here was simplistic, there may be implications for the opinion polling industry. While sophisticated methodologies exist for recruiting and weighting samples with respect to demographic characteristics, it is not clear that polling professionals to the same with respect to personality variables. The current findings suggest it may be desirable to do that, at least for Openness to Experience, given that high Openness scorers may be overrepresented in online panels in comparison to the wider population (irrespective of demographic similarity).

\section{Conclusions}

It is clear that 'internet samples' recruited in different ways may have different personality characteristics. In particular, volunteers are likely to have higher Openness to Experience scores than people being paid to participate or students receiving course credit for doing so. The differences are relatively small in magnitude, a point that led previous researchers to dismiss similar findings as being unlikely to have important implications for research. In this instance, it was demonstrated that a personality bias could affect research outcomes, to the extent that a phenomenon was detected with one type of sample but not another. On this basis, it is recommended that researchers doing internet-mediated research where Openness to Experience may be relevant should take this bias into account. 


\section{References}

Buchanan, T., Johnson, J. A., \& Goldberg, L. R. (2005). Implementing a Five-Factor Personality Inventory for Use on the Internet. European Journal of Psychological Assessment, 21(2), 115-127. doi:10.1027/1015-5759.21.2.115

Carney, D. R., Jost, J. T., Gosling, S. D., \& Potter, J. (2008). The Secret Lives of Liberals and Conservatives: Personality Profiles, Interaction Styles, and the Things They Leave Behind: Liberals and Conservatives. Political Psychology, 29(6), 807-840. doi:10.1111/j.1467-9221.2008.00668.x

Costa, P. T., \& McCrae, R. R. (1992). Revised NEO Personality Inventory (NEO PIR) and NEO Five-Factor Inventory (NEO FFI): Professional Manual. Odessa, FL: Psychological Assessment Resources.

Crone, D. L., \& Williams, L. A. (2016). Crowdsourcing participants for psychological research in Australia: A test of Microworkers. Australian Journal of Psychology. doi:10.1111/ajpy.12110

Dollinger, S. J., \& Leong, F. T. L. (1993). Volunteer bias and the five-factor model. The Journal of Psychology, 127(1), 29-36. doi:10.1080/00223980.1993.9915540

Goldberg, L. R. (1999). A broad-bandwidth, public domain, personality inventory measuring the lower-level facets of several five-factor models. In I. Mervielde, I.J. Deary, F. De Fruyt, \& F. O. (Eds.), Personality Psychology in Europe Vol. 7 (pp. 7-28). Tilburg, The Netherlands: Tilburg University Press. Retrieved from http://projects.ori.org/lrg/PDFs_papers/A broad-bandwidth inventory.pdf

Hauser, D. J., \& Schwarz, N. (2016). Attentive Turkers: MTurk participants perform better on online attention checks than do subject pool participants. Behavior Research Methods, 48, 400-407. doi:10.3758/s13428-015-0578-z

Hays, R. D., Liu, H., \& Kapteyn, A. (2015). Use of Internet panels to conduct surveys. 
Behavior Research Methods, 47(3), 685-690. doi:10.3758/s13428-015-0617-9

John, O. P., Naumann, L. P., \& Soto, C. J. (2008). Paradigm Shift to the Integrative Big-Five Trait Taxonomy: History, Measurement, and Conceptual Issues. In O. P. John, R. W. Robins, \& L. A. Pervin (Eds.), Handbook of personality: Theory and research (pp. 114-158). New York, NY: Guilford Press.

Kennedy, C., Mercer, A., Keeter, S., Hatley, N., McGeeney, K., \& Gimenez, A. (2016). Evaluating online nonprobability surveys. Retrieved 12th January, 2018 from http://www.pewresearch.org/files/2016/04/Nonprobability-report-May2016-FINAL.pdf

Khazaal, Y., van, S., Mathias, Chatton, A., Achab, S., Zullino, D., Rothen, S., ... Thorens, G. (2014). Does Self-Selection Affect Samples' Representativeness in Online Surveys? An Investigation in Online Video Game Research. Journal of Medical Internet Research, 16(7), e164. doi:10.2196/jmir.2759

Lowry, P. B., D’Arcy, J., Hammer, B., \& Moody, G. D. (2016). “Cargo Cult” science in traditional organization and information systems survey research: A case for using nontraditional methods of data collection, including Mechanical Turk and online panels. The Journal of Strategic Information Systems, 25(3), 232-240. doi:10.1016/j.jsis.2016.06.002

Matthijsse, S. M., Leeuw, E. D. D., \& Hox, J. J. (2015). Internet Panels, Professional Respondents, and Data Quality. Methodology, 11(3), 81-88. doi:10.1027/16142241/a000094

Oakes, W. (1972). External validity and the use of real people as subjects. American Psychologist, 27(10), 959-962. doi:10.1037/h0033454

Reips, U.-D. (2000). The Web experiment method: Advantages, disadvantages, and 
solutions. In M. H. Birnbaum (Ed.), Psychological Experiments on the Internet (pp. 89-118). San Diego, CA: Academic Press.

Rife, S. C., Cate, K. L., Kosinski, M., \& Stillwell, D. (2014). Participant recruitment and data collection through Facebook: the role of personality factors. International Journal of Social Research Methodology. doi:10.1080/13645579.2014.957069

Stewart, N., Ungemach, C., Harris, A. J. L., Bartels, D. M., Newell, B. R., Paolacci, G., \& Chandler, J. (2015). The average laboratory samples a population of 7,300 Amazon Mechanical Turk workers. Judgment and Decision Making, 10(5), 479491. Retrieved from http://www.ucl.ac.uk/lagnadolab/publications/harris/StewartEtAl_JDM_MTurk.pdf

Sturgis, P., Kuha, J., Baker, N., Callegaro, M., Fisher, S., Green, J., . . Smith, P. (2017). An assessment of the causes of the errors in the 2015 UK general election opinion polls. Journal of the Royal Statistical Society: Series A (Statistics in Society), [RSSA12329]). doi:10.1111/rssa.12329

Thomas, K. A., \& Clifford, S. (2017). Validity and Mechanical Turk: An assessment of exclusion methods and interactive experiments. Computers in Human Behavior, 77, 184-197. doi:10.1016/j.chb.2017.08.038

Van Lange, P. A. M., Schippers, M., \& Balliet, D. (2011). Who volunteers in psychology experiments? An empirical review of prosocial motivation in volunteering. Personality and Individual Differences, 51(3), 279-284. doi:10.1016/j.paid.2010.05.038 
Table 1

Tables

Demographic Data for Study 1

\begin{tabular}{|c|c|c|c|c|c|c|}
\hline & \multicolumn{3}{|c|}{ Analysis 1} & \multicolumn{3}{|c|}{ Analysis 2} \\
\hline & \multicolumn{3}{|c|}{ Condition } & \multicolumn{3}{|c|}{ Condition } \\
\hline & All & 1 (volunteers) & 2 (course requirement) & All & 1 (volunteers) & 2 (course requirement) \\
\hline $\bar{N}$ & 326 & 234 & 92 & 6693 & 2512 & 4181 \\
\hline \multicolumn{7}{|l|}{ Sex } \\
\hline Men & $102(31.3 \%)$ & $87(37.2 \%)$ & $15(16.3 \%)$ & $2226(33.3 \%)$ & $889(35.4 \%)$ & $1337(32.0 \%)$ \\
\hline Women & $219(67.2 \%)$ & $144(61.5 \%)$ & $75(81.5 \%)$ & $4327(64.6 \%)$ & $1565(62.3 \%)$ & $2762(66.0 \%)$ \\
\hline Unanswered & $5(1.5 \%)$ & $3(1.3 \%)$ & $2(2.2 \%)$ & $140(2.1 \%)$ & $58(2.3 \%)$ & $82(2.0 \%)$ \\
\hline \multicolumn{7}{|l|}{ Age } \\
\hline Modal age group & $16-20(60.1 \%)$ & $16-20(53.4 \%)$ & $16-20(77.2 \%)$ & $16-20(49.3 \%)$ & $16-20(22.0 \%)$ & $16-20(65.7 \%)$ \\
\hline Age range & $16-55$ & $16-55$ & $16-45$ & $16-85$ & $16-85$ & $16-85$ \\
\hline Unanswered & $0(0 \%)$ & $0(0 \%)$ & $0(0 \%)$ & $0(0 \%)$ & $0(0 \%)$ & $0(0 \%)$ \\
\hline \multicolumn{7}{|l|}{ Location } \\
\hline USA & $0(0 \%)$ & $0(0 \%)$ & $0(0 \%)$ & $6693(100 \%)$ & $2512(100 \%)$ & $4181(100 \%)$ \\
\hline UK & $326(100 \%)$ & $234(100 \%)$ & $92(100 \%)$ & $0(0 \%)$ & $0(0 \%)$ & $0(0 \%)$ \\
\hline Unanswered & $0^{1}(0 \%)$ & $0(0 \%)$ & $0(0 \%)$ & $0(0 \%)$ & $0(0 \%)$ & $0(0 \%)$ \\
\hline \multicolumn{7}{|l|}{ Route to participation } \\
\hline Doing as part of some class & $92(28.2 \%)$ & $0(0 \%)$ & $92(100 \%)$ & $4181(62.5 \%)$ & $0(0 \%)$ & $4181(100 \%)$ \\
\hline Found through search engine & $95(29.1 \%)$ & $95(40.6 \%)$ & $0(0 \%)$ & $798(11.9 \%)$ & $798(31.8 \%)$ & $0(0 \%)$ \\
\hline Got link from a friend & $64(19.6 \%)$ & $64(27.4 \%)$ & $0(0 \%)$ & $448(6.7 \%)$ & $448(17.8 \%)$ & $0(0 \%)$ \\
\hline Followed link from another site & $50(15.3 \%)$ & $50(21.4 \%)$ & $0(0 \%)$ & $901(13.5 \%)$ & $901(35.9 \%)$ & $0(0 \%)$ \\
\hline Other & $25(7.7 \%)$ & $25(10.7 \%)$ & $0(0 \%)$ & $322(4.8 \%)$ & $322(12.8 \%)$ & $0(0 \%)$ \\
\hline
\end{tabular}




\begin{tabular}{|c|c|c|c|c|c|c|}
\hline \multicolumn{7}{|l|}{ Highest level of education } \\
\hline Primary Education & $8(2.5 \%)$ & $6(2.6 \%)$ & $2(2.2 \%)$ & $628(9.4 \%)$ & $85(3.4 \%)$ & $543(13.0 \%)$ \\
\hline Secondary Education & $90(27.6 \%)$ & $61(26.1 \%)$ & $29(31.5 \%)$ & $2396(35.8 \%)$ & $496(19.8 \%)$ & $1900(45.4 \%)$ \\
\hline Vocational / Technical college & $29(8.9 \%)$ & $17(7.3 \%)$ & $12(13.0 \%)$ & $134(2.0 \%)$ & $83(3.3 \%)$ & $51(1.2 \%)$ \\
\hline Some college / University & $110(33.7 \%)$ & $81(34.6 \%)$ & $29(31.5 \%)$ & $1767(26.4 \%)$ & $606(24.1 \%)$ & $1161(27.8 \%)$ \\
\hline College / University Graduate & $64(19.6 \%)$ & $45(19.2 \%)$ & $19(20.7 \%)$ & $1016(15.2 \%)$ & $670(26.7 \%)$ & $346(8.3 \%)$ \\
\hline Some Postgraduate & $13(4.0 \%)$ & $13(5.6 \%)$ & $0(0 \%)$ & $324(4.8 \%)$ & $205(8.2 \%)$ & $119(2.8 \%)$ \\
\hline Postgraduate / Professional Degree & $11(3.4 \%)$ & $11(4.7 \%)$ & $0(0 \%)$ & $417(6.2 \%)$ & $362(14.4 \%)$ & $55(1.3 \%)$ \\
\hline Unanswered & $1(0.3 \%)$ & $0(0 \%)$ & $1(1.1 \%)$ & $11(0.2 \%)$ & $5(0.2 \%)$ & $6(0.1 \%)$ \\
\hline \multicolumn{7}{|l|}{ Occupation } \\
\hline Employed for Wages & $8(2.5 \%)$ & $0(0 \%)$ & $8(8.7 \%)$ & $2243(33.5 \%)$ & $1224(48.7 \%)$ & $1019(24.4 \%)$ \\
\hline Self-employed & $1(0.3 \%)$ & $0(0 \%)$ & $1(1.1 \%)$ & $295(4.4 \%)$ & $222(8.8 \%)$ & $73(1.7 \%)$ \\
\hline Unemployed & $5(1.5 \%)$ & $0(0 \%)$ & $5(5.4 \%)$ & $301(4.5 \%)$ & $131(5.2 \%)$ & $170(4.1 \%)$ \\
\hline Home-maker & $0(0 \%)$ & $0(0 \%)$ & $0(0 \%)$ & $97(1.4 \%)$ & $65(2.6 \%)$ & $32(0.8 \%)$ \\
\hline Student & $311(95.4 \%)$ & $234(100 \%)$ & $77(83.7 \%)$ & $3543(52.9 \%)$ & $712(28.3 \%)$ & $2831(67.7 \%)$ \\
\hline Retired & $0(0 \%)$ & $0(0 \%)$ & $0(0 \%)$ & $66(1.0 \%)$ & $61(2.4 \%)$ & $5(0.2 \%)$ \\
\hline Unable to work & $0(0 \%)$ & $0(0 \%)$ & $0(0 \%)$ & $65(1.0 \%)$ & $56(2.2 \%)$ & $9(0.2 \%)$ \\
\hline Unanswered & $1(0.3 \%)$ & $0(0 \%)$ & $1(1.1 \%)$ & $83(1.2 \%)$ & $41(1.6 \%)$ & $42(1.0 \%)$ \\
\hline
\end{tabular}

Note. Percentages may not sum exactly to $100 \%$ due to rounding errors.

${ }^{l}$ One participant in Study 1 Condition 2 did not report location but was known to be in the UK. 
Table 2

Descriptive Statistics for Personality Scales, Study 1

Analysis 1

Analysis 2

Range Range

\begin{tabular}{|c|c|c|c|c|c|c|c|c|c|c|c|c|c|c|}
\hline ble & $n$ & $M$ & $S D$ & $\alpha$ & Potential & Actual & Skew & $n$ & $M$ & $S D$ & $\alpha$ & Potential & Actual & Skew \\
\hline stra & 326 & 8.97 & 7.26 & .87 & $9-45$ & $9-45$ & -0.10 & 6693 & 29.51 & 7.43 & .86 & $9-45$ & $9-45$ & 4 \\
\hline
\end{tabular}

$9-45$

$\begin{array}{ll}9-45 & -0.24 \\ 7-35 & -0.77\end{array}$

$\begin{array}{lllll}326 & 26.47 & 4.44 & .71 & 7-35\end{array}$

$12-35 \quad-0.64$

$\begin{array}{llll}6693 & 27.62 & 4.49 & .75\end{array}$

$7-35$

$7-35 \quad-0.77$

Conscientiousness

$\begin{array}{lllll}326 & 31.82 & 6.99 & .83 & 10-50\end{array}$

$\begin{array}{llll}6693 & 35.56 & 6.99 & .84\end{array}$

$10-50$

$10-50 \quad-0.29$

Neuroticism

$\begin{array}{llllll}326 & 23.13 & 6.73 & .85 & 8-40\end{array}$

$8-40 \quad 0.29$

$\begin{array}{llllll}6693 & 21.33 & 6.72 & .84 & 8-40\end{array}$

$8-40 \quad 0.30$

Openness to Experience

$\begin{array}{llllll}326 & 26.52 & 5.11 & .75 & 7-35\end{array}$

$11-35 \quad-0.41$

$\begin{array}{llllll}6693 & 26.09 & 5.28 & .74 & 7-35\end{array}$

$7-35 \quad-0.42$


Table 3

Volunteer and Participation Scheme Personality Scores, Study 1

\begin{tabular}{|c|c|c|c|c|c|c|c|c|c|c|}
\hline & \multicolumn{2}{|c|}{ Volunteers } & \multicolumn{2}{|c|}{ Participation Scheme } & \multirow[b]{2}{*}{$t$} & \multirow[b]{2}{*}{$d f$} & \multirow[b]{2}{*}{$p$} & \multicolumn{2}{|c|}{$95 \% \mathrm{CI}$} & \multirow[b]{2}{*}{ Cohen's $d$} \\
\hline & $M$ & $S D$ & $M$ & $S D$ & & & & $L L$ & $U L$ & \\
\hline Extraversion & 29.06 & 7.71 & 28.73 & 6.00 & 0.42 & 212.4 & .68 & -1.25 & 1.92 & .05 \\
\hline Agreeableness & 26.51 & 4.71 & 26.36 & 3.69 & 0.30 & 210.9 & .76 & -0.82 & 1.12 & .04 \\
\hline Conscientiousness & 31.72 & 7.17 & 32.08 & 6.56 & -0.42 & 324 & .68 & -2.05 & 1.34 & -.05 \\
\hline Neuroticism & 23.16 & 6.98 & 23.07 & 6.07 & 0.12 & 190.3 & .91 & -1.45 & 1.63 & .01 \\
\hline Openness to Experience & 26.97 & 5.05 & 25.37 & 5.10 & 2.56 & 324 & .01 & 0.36 & 2.83 & .32 \\
\hline
\end{tabular}

Note. $\mathrm{CI}=$ Confidence Interval; $\mathrm{LL}=$ Lower Limit; UL $=$ Upper Limit. For Extraversion, Agreeableness and Neuroticism, adjusted $d f$ used due to heterogeneity of variance. 
Table 4

Comparison of Study 1 Participants Completing Online Test as a Class Requirement With Those Who Are Volunteers

\begin{tabular}{|c|c|c|c|c|c|c|c|c|c|c|}
\hline & \multicolumn{4}{|c|}{ Estimates } & \multirow[b]{3}{*}{$F_{(1,6548)}$} & \multirow[b]{3}{*}{$p$} & \multirow{2}{*}{\multicolumn{3}{|c|}{ Estimated Differences }} & \multirow{3}{*}{$\begin{array}{c}\text { Partial eta } \\
\text { squared }\end{array}$} \\
\hline & \multicolumn{2}{|c|}{ Volunteers } & \multicolumn{2}{|c|}{ Class Requirement } & & & & & & \\
\hline & $M$ & $S E$ & $M$ & $S E$ & & & $M$ & $L L$ & $U L$ & \\
\hline Extraversion & 28.29 & 0.17 & 30.25 & 0.13 & 79.71 & .000 & -0.20 & -2.39 & -1.53 & 0.01 \\
\hline Agreeableness & 26.95 & 0.10 & 27.62 & 0.08 & 26.71 & .000 & -0.67 & -0.93 & -0.42 & 0.00 \\
\hline Conscientiousness & 34.09 & 0.15 & 36.18 & 0.12 & 107.80 & .000 & -2.09 & -2.49 & -1.70 & 0.02 \\
\hline Neuroticism & 21.98 & 0.15 & 20.20 & 0.11 & 85.20 & .000 & 1.78 & 1.40 & 2.16 & 0.01 \\
\hline Openness to Experience & 27.30 & 0.11 & 25.10 & 0.09 & 210.10 & .000 & 2.20 & 1.90 & 2.50 & 0.03 \\
\hline
\end{tabular}

Note. $\mathrm{CI}=$ Confidence Interval; $\mathrm{LL}=$ Lower Limit; $\mathrm{UL}=$ Upper Limit. 
Table 5

Analyses of Covariance Examining Effect of Class Requirement to Participate, Sex and Age Group on Personality Variables

\begin{tabular}{|c|c|c|c|c|}
\hline & Variable & $F_{(1,6548)}$ & $p$ & $\begin{array}{l}\text { Partial eta } \\
\text { squared }\end{array}$ \\
\hline \multirow[t]{4}{*}{ Extraversion } & Age Group & 0.48 & 0.489 & 0.00 \\
\hline & Sex & 0.00 & 0.957 & 0.00 \\
\hline & Class Requirement? & 79.71 & 0.000 & 0.01 \\
\hline & Sex x Class Requirement & 0.73 & 0.393 & 0.00 \\
\hline \multirow[t]{4}{*}{ Agreeeableness } & Age Group & 169.53 & 0.000 & 0.03 \\
\hline & Sex & 164.13 & 0.000 & 0.02 \\
\hline & Class Requirement? & 26.71 & 0.000 & 0.00 \\
\hline & Sex x Class Requirement & 0.03 & 0.859 & 0.00 \\
\hline \multirow[t]{4}{*}{ Conscientiousness } & Age Group & 314.46 & 0.000 & 0.05 \\
\hline & Sex & 36.37 & 0.000 & 0.01 \\
\hline & Class Requirement? & 107.80 & 0.000 & 0.02 \\
\hline & Sex x Class Requirement & 0.87 & 0.351 & 0.00 \\
\hline \multirow[t]{4}{*}{ Neuroticism } & Age Group & 218.93 & 0.000 & 0.03 \\
\hline & Sex & 222.22 & 0.000 & 0.03 \\
\hline & Class Requirement? & 85.20 & 0.000 & 0.01 \\
\hline & Sex x Class Requirement & 15.08 & 0.000 & 0.00 \\
\hline \multirow[t]{4}{*}{ Openness to Experience } & Age Group & 37.83 & 0.000 & 0.01 \\
\hline & Sex & 44.16 & 0.000 & 0.01 \\
\hline & Class Requirement? & 210.10 & 0.000 & 0.03 \\
\hline & Sex x Class Requirement & 3.75 & 0.053 & 0.00 \\
\hline
\end{tabular}


Table 6

Demographic Data for Studies 2 and 3

\begin{tabular}{|c|c|c|c|c|}
\hline & \multirow[t]{2}{*}{ Study 2} & \multicolumn{3}{|c|}{ Study 3} \\
\hline & & \multicolumn{3}{|c|}{ Condition } \\
\hline$N$ & 1179 & 10427 & 247 & 298 \\
\hline \multicolumn{5}{|l|}{ Sex } \\
\hline Men & $423(35.9 \%)$ & $3754(36.0 \%)$ & $111(44.9 \%)$ & $137(46.0 \%)$ \\
\hline Women & $733(62.2 \%)$ & $6571(63.0 \%)$ & $136(55.1 \%)$ & $161(54.0 \%)$ \\
\hline Unanswered & $23(2.0 \%)$ & $102(1.0 \%)$ & $0(0 \%)$ & $0(0 \%)$ \\
\hline Age range & $16-80$ & $16-75$ & $18-25$ & $18-25$ \\
\hline Mean age $(S D)$ & - & $25.79(10.55 \%)$ & $20.8(2.19)$ & $21.7(2.23)$ \\
\hline Unanswered & $0(0 \%)$ & $0(0 \%)$ & $0(0 \%)$ & $0(0 \%)$ \\
\hline \multicolumn{5}{|l|}{ Location } \\
\hline USA & $804(68.2 \%)$ & $6448(61.8 \%)$ & $247(100 \%)$ & $298(100 \%)$ \\
\hline UK & $133(11.3 \%)$ & $1089(10.4 \%)$ & $0(0 \%)$ & $0(0 \%)$ \\
\hline Followed link from another site & $50(4.2 \%)$ & $833(8.0 \%)$ & $0(0 \%)$ & $0(0 \%)$ \\
\hline Other & $75(6.4 \%)$ & $781(75 \%)$ & $0(0 \%)$ & $0(0 \%)$ \\
\hline Unanswered & $6(0.5 \%)$ & $10(0.1 \%)$ & $0(0 \%)$ & $0(0 \%)$ \\
\hline Qualtrics panel & - & $298(2.9 \%)$ & $0(0 \%)$ & $298(100 \%)$ \\
\hline
\end{tabular}


Highest level of education

Primary Education

Secondary Education

Vocational / Technical college

Some college / University

College / University Graduate

Some Postgraduate

Postgraduate / Professional Degree

Unanswered

\section{Occupation}

Employed for Wages

Self-employed

Unemployed

Home-maker

Student

Retired

Unable to work

Unanswered

$$
\begin{aligned}
& 48(4.1 \%) \\
& 419(35.5 \%) \\
& 45(3.8 \%) \\
& 379(32.1 \%) \\
& 160(13.6 \%) \\
& 67(5.7 \%) \\
& 61(5.2 \%) \\
& 0(0 \%)
\end{aligned}
$$

\section{$393(33.3 \%)$}

$44(3.7 \%)$

$50(4.2 \%)$

$11(0.9 \%)$

$643(54.5 \%)$

$5(0.4 \%)$

$4(0.3 \% 0$ $29(2.5 \%)$

\section{$1085(10.4 \%)$ \\ $2517(24.1 \%)$ \\ $336(3.2 \%)$ \\ $3332(32.0 \%)$ \\ $1655(15.9 \%)$ \\ $495(4.7 \%)$ \\ $998(9.5 \%)$ \\ $9(0.1 \%)$}

$3764(36.1 \%)$

$471(4.5 \%)$

$382(3.75)$

$138(1.3 \%)$

$5444(52.2 \%)$

$85(0.8 \%)$

$131(1.3 \%)$

$12(0.1 \%)$

\section{$2(0.8 \%)$ \\ $50(20.2 \%)$ \\ $2(0.8 \%)$ \\ $126(51.0 \%)$ \\ $51(20.6 \%)$ \\ $7(2.8 \%)$ \\ $9(3.6 \%)$ \\ $0(0 \%)$}

$91(36.8 \%)$

$4(1.6 \%)$

$0(0 \%)$

$0(0 \%)$

$152(61.5 \%)$

$0(0 \%)$

$0(0 \%)$

$0(0 \%)$
$8(2.7 \%)$

$72(24.2 \%)$

7 (2.3\%)

$126(42.3 \%)$

$59(19.8 \%)$

$9(3.0 \%)$

$17(5.7 \%)$

$0(0 \%)$

$142(47.7 \%)$ $16(5.4 \%)$

$0(0 \%)$

$0(0 \%)$

$140(47.0 \%)$

$0(0 \%)$

$0(0 \%)$

$0(0 \%)$

Note. Percentages may not sum exactly to $100 \%$ due to rounding errors. 
Table 7

Descriptive Statistics for Personality Scales, Study 2

\begin{tabular}{lccccccc} 
& & & & & \multicolumn{2}{c}{ Range } & \\
\cline { 6 - 7 } Variable & $N$ & $M$ & $S D$ & $\alpha$ & Potential & Actual & Skew \\
\hline Extraversion & 1179 & 29.28 & 7.51 & .87 & $9-45$ & $9-45$ & -0.30 \\
Agreeableness & 1179 & 27.21 & 4.63 & .75 & $7-35$ & $9-35$ & -0.66 \\
Conscientiousness & 1179 & 34.41 & 7.23 & .84 & $10-50$ & $11-50$ & -0.30 \\
Neuroticism & 1179 & 22.29 & 6.86 & .83 & $8-40$ & $8-40$ & 0.37 \\
Openness to Experience & 1179 & 25.74 & 5.57 & .77 & $7-35$ & $8-35$ & -0.40 \\
Non-political Openness to Experience & 1179 & 18.97 & 4.30 & .76 & $5-25$ & $5-25$ & -0.61 \\
\hline
\end{tabular}


Table 8

Binary Logistic Regression: Personality and Demographic Predictors of Voting Preference

\begin{tabular}{lrrrrrrl}
\hline & \multicolumn{1}{c}{$B$} & S.E. & Wald & $d f$ & $p$ & $\operatorname{Exp}(B)$ & $95 \%$ CI for $\operatorname{Exp}(B)$ \\
\hline Openness to Experience (non-political) & -0.12 & 0.03 & 23.01 & 1 & .000 & 0.89 & {$[0.84,0.93]$} \\
Extraversion & 0.03 & 0.02 & 3.00 & 1 & .083 & 1.03 & {$[1.00,1.06]$} \\
Agreeableness & 0.01 & 0.03 & 0.05 & 1 & .825 & 1.01 & {$[0.96,1.06]$} \\
Conscientiousness & 0.04 & 0.02 & 4.77 & 1 & .029 & 1.04 & {$[1.00,1.08]$} \\
Neuroticism & 0.01 & 0.02 & 0.21 & 1 & .645 & 1.01 & {$[0.97,1.05]$} \\
Sex $(\mathrm{M}=1, \mathrm{~F}=2)$ & -0.70 & 0.23 & 9.47 & 1 & .002 & 0.50 & {$[0.32,0.78]$} \\
Age group & -0.13 & 0.06 & 4.37 & 1 & .037 & 0.88 & {$[0.78,0.99]$} \\
Constant & 0.90 & 1.15 & 0.61 & 1 & .435 & 2.46 & \\
\hline
\end{tabular}


Table 9

Descriptive Statistics for Personality Scales, Study 3

\begin{tabular}{lccccccc}
\hline & & & & \multicolumn{4}{c}{ Range } \\
\cline { 6 - 7 } Variable & $N$ & $M$ & $S D$ & $\alpha$ & Potential & Actual & Skew \\
\hline BFI Openness to Experience & 10285 & 38.09 & 6.10 & .78 & $10-50$ & $12-50$ & -0.43 \\
Extraversion & 10427 & 28.93 & 7.25 & .87 & $9-45$ & $9-45$ & -0.21 \\
Agreeableness & 10427 & 27.65 & 4.32 & .73 & $7-35$ & $7-35$ & -0.73 \\
Conscientiousness & 10427 & 35.25 & 7.08 & .84 & $10-50$ & $11-50$ & -0.30 \\
Neuroticism & 10427 & 21.72 & 6.71 & .83 & $8-40$ & $8-40$ & 0.30 \\
Openness to Experience & 10427 & 25.90 & 5.21 & .74 & $7-35$ & $7-35$ & -0.39 \\
\hline
\end{tabular}


Table 10

Big Five Inventory Openness to Experience scores for online volunteers and paid panellists

\begin{tabular}{|c|c|c|c|c|c|c|c|c|c|c|}
\hline \multirow[b]{2}{*}{ Sample } & \multicolumn{2}{|c|}{ Republican } & voters & \multicolumn{2}{|c|}{ Democrat } & voters & \multirow[b]{2}{*}{$t$} & \multirow[b]{2}{*}{$d f$} & \multirow[b]{2}{*}{$p$} & \multirow[b]{2}{*}{ Cohen's $d$} \\
\hline & $N$ & $M$ & $S D$ & $N$ & $M$ & $S D$ & & & & \\
\hline Online volunteers & 40 & 37.42 & 6.64 & 120 & 39.83 & 5.70 & 2.22 & 158 & .028 & -0.39 \\
\hline Paid panellists & 65 & 36.26 & 5.84 & 150 & 37.61 & 5.97 & 1.53 & 213 & .13 & -0.23 \\
\hline
\end{tabular}

